\title{
Etiological Difficulty of Gynecomastia in a Patient on Several Substances
}

\author{
Louzolo-Kimbembe R*, Ismail Z, Rafi S, El Mghari G, El Ansari N
}

Department of Endocrinology, Diabetology, Metabolic Diseases and Nutrition Mohammed VI University Hospital of Marrakesh, Morocco

DOI: $10.36347 /$ sjams.2021.v09i03.002

| Received: 17.02.2021 | Accepted: 28.02.2021 | Published: 03.03.2021

*Corresponding author: Louzolo-Kimbembe $\mathrm{R}$

Abstract

Case Report

Gynecomastia is a benign overgrowth of the male mammary gland that results from an increased ratio of estrogen to androgen action. It must be distinguished from lipomastia and mammary carcinoma. Gynecomastia is either physiological at different stages of life (birth, adolescence, senescence), or secondary to diseases causing a drop in androgens/an increase in estrogen, or related to the taking of drugs or narcotics. Nowadays, the list of drugs associated with gynecomastia is well known, and for many years some experimental cases of cannabis use in male mammals have revealed the onset of gynecomastia with falling testosterone levels.

Keywords: Gynecomastia, testosterone, estradiol, spironolactone, cannabis.

Copyright $\odot 2021$ The Author(s): This is an open-access article distributed under the terms of the Creative Commons Attribution 4.0 International License (CC BY-NC 4.0) which permits unrestricted use, distribution, and reproduction in any medium for non-commercial use provided the original author and source are credited.

\section{INTRODUCTION}

Gynecomastia is a uni or bilateral hyperplasia of the mammary glandular tissue in humans resulting from a systemic or local imbalance between androgens and estrogens to the benefit of the latter. Gynecomastia is not a disease in itself but is a symptom of a hormonal imbalance with multiple causes, endocrine, tumor, drug or idiopathic when all other causes are eliminated. Drugs can be associated with gynecomastia, some more than others. Likewise, the consumption of narcotic drugs such as cannabis ultimately leads to bronchopulmonary and cardiovascular consequences, and other consequences including endocrine, in particular gynecomastia [1]. We report a case of bilateral gynecomastia in a patient who is a chronic cannabis user and is taking spironolactone.

\section{Case Report}

37-year-old patient hospitalized for diffuse interstitial lung disease in the fibrosis stage. Known chronic tobacco 24 pack year, concept of cannabis use for 12 years. The patient had been put by a cardiologist on spironolactone $50 \mathrm{mg} \mathrm{/} \mathrm{day} \mathrm{for} \mathrm{pulmonary}$ hypertension on chronic cor pulmonale. During the clinical examination of the patient, a bilateral gynecomastia has been objectified.

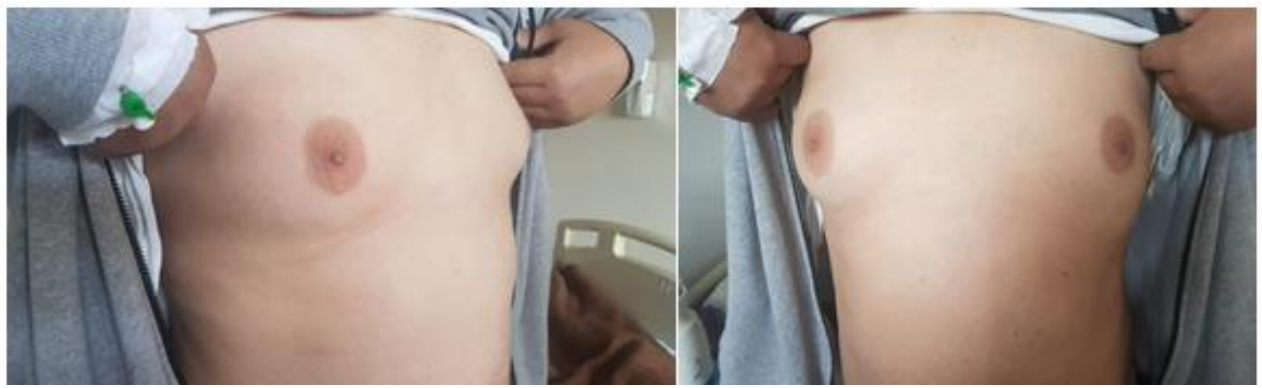

Fig-1: bilateral gynecomastia face-profile

Confirmed by breast ultrasound which noted bilateral glandular hypertrophy. The assessment carried out: renal, hepatic, thyroid, tumor (HCG dosage) was normal, and the rest of the hormonal assessment revealed normal prolactin but barely normal testosterone level, with a high estradiol level at 52ng / L for a normal in mens between 7.6 and 42.6 according to the reference values of our laboratory. Further testicular ultrasound ruled out a patent testicular tumor, confirming the clinical testicular examination. Finally 
Louzolo-Kimbembe R et al; Sch J App Med Sci, Mar, 2021; 9(3): 306-308

an adrenal tumor, notably a feminizing adrenal cortical carcinoma, was ruled out by adrenal computed tomography, although the clinic was already not in favor. The patient did not report a decrease in libido or erectile dysfunction.

\section{DISCUSSION}

Gynecomastia is a benign overgrowth of the glandular tissue of the breast and may be the first symptom of an underlying disease, although there is controversy regarding the clinical importance of further investigation in men who develop gynecomastia [2]. Even if an obvious cause of gynecomastia is suspected (drug intake, narcotic intake as in our case) it should not prevent further investigation, in fact studies have objectified underlying pathologies despite fairly obvious causes [2]. Gynecomastia in our patient being non-physiological, it was therefore necessary to proceed methodically by ruling out pathologies with low androgen levels, in particular primary or secondary hypogonadisms, hyperprolactinemia, pathologies with high estrogen levels, in particular testicular and adrenal tumors ( feminizing adrenal cortical carcinoma), pathologies with a high SHBG (sex hormone binding globulin) level, in particular hyperthyroidism and hepatic cirrhosis and general pathologies such as renal failure. Among the remaining incriminated causes, our patient was on treatment with spironolactone and known chronic cannabis user. Spironolactone is labeled as a drug very associated with gynecomastia. It is because spironolactone inhibits the production of testosterone in the testes, increases aromatization and therefore the peripheral conversion of testosterone to estradiol and binds to androgen receptors in certain tissues, thus acting as an antiandrogenic substance [3].

The onset of gynecomastia with spironolactone is duration and dose dependent. The minimum duration of the onset of gynecomastia with spironolactone is at least two months [4]. Out of a series of 699 patients followed for essential hypertension on spironolactone, $13 \%$ or 91 patients developed gynecomastia but at varying doses and durations, the duration of treatment for the development of gynecomastia varied from 2 to 100 months but was shorter for daily doses greater than or equal to $150 \mathrm{mg}$ of spironolactone (between 9 and 12 months) than for daily doses less than or equal to $50 \mathrm{mg}$ of spironolactone (between 20 and 27 months) [4].

Other studies have noted that gynecomastia can develop as early as 1 month after initiating spironolactone, dose dependent, and can regress within 3 to 6 months after stopping spironolactone $[5,6]$. Also, many studies make the connection between the consumption of cannabis and the appearance of gynecomastia, the mechanism still not being well elucidated, the hypothesis is based on the structural similarity between the major active component of cannabis, tetrahydrocannabinol (THC) and estradiol [7,
8]. A study carried out in cannabis users had established a direct link with the onset of gynecomastia [7], but another study failed to formally establish a cause and effect relationship [8]. However, regression of gynecomastia has been observed in people who were able to abstain from cannabis use, and pathological examination of the breast tissue of cannabis users revealed florid ductal proliferation [9]. Today, with the decriminalization of cannabis in some countries, for recreational or therapeutic purposes, several cases of gynecomastia in men who are chronic cannabis users are described. In the USA, the American Society for Aesthetic and Plastic Surgery (ASAPS), reported an exponential increase in cases of breast reduction surgery among cannabis users, more than 30,000 surgical interventions for breast reduction between 2014 and 2015 [10].

Studies comparing hormone levels in regular cannabis users with non-users nevertheless suggest a deleterious effect of this substance. The results in animals are less equivocal: cannabis does lower testosterone levels, decrease testicular size and produce poor quality sperm. Physiological changes which can therefore have repercussions on the growth of the mammary glands [10].

\section{CONCLUSION}

Spironolactone is very associated with cases of gynecomastia by the mechanisms described above, the dosage should be adjusted and the duration of treatment to be minimized, or even substituted if possible. For our patient, spironolactone was deemed necessary for the treatment of his pulmonary hypertension, but the dose was reduced and a thiazide diuretic was added.

If spironolactone is implicated in gynecomastia in our patient, his chronic consumption of cannabis for 12 years, in view of the supposed cause and effect links, could therefore already have induced gynecomastia to which the effect of spironolactone would have been added, but it is not easy to separate things, especially since an underlying pathology may exist but the combined effect of spironolactone and cannabis on the synthesis and metabolism of testosterone, their repercussion on the functioning of the gonadotropic axis complicates the picture.

\section{REFERENCES}

1. Vidrio. Effets somatiques à court et à long terme de la consommation de cannabis, Analyse, chap. 1996; 10: 215-232.

2. Mieritz MG, Christiansen $P$, Jensen MB. Gynaecomastia in 786 adult men: clinical and biochemical findings, European Journal of Endocrinology; 2017

3. De Barros A, De Castro Moura Sampio M, Gyecomastia: Physiopathology, evaluation and treatment, Sao Paulo Medical Journal; 2012 
Louzolo-Kimbembe R et al; Sch J App Med Sci, Mar, 2021; 9(3): 306-308

4. Jeunemaitre X, Chatellier G, Kreft-Jais C. Efficacy and tolerance of spironolactone in essential hypertension, American Journal of Cardiology; 1987.

5. Deepinder F, Braunstein G, Drug-induced gynecomastia: an evidence-based review, Expert Opinion on Drug Safety; 2012

6. Rose LI, Underwood RH, Newmark SR. Pathophysiology of spironolactone-induced gynecomastia, Annals of Internal Medicine; 1977

7. Harmon J, Aliapoulios MA, Gynecomastia in marihuana users, The New England Journal of Medicine; 1972.
8. Cates W, Pope JN. Gynecomastia and cannabis smoking, The American Journal of Surgery; 1977.

9. Harmon JW, Aliapoulios MA, Marijuana induced gynecomastia: clinical and laboratory experience, Surgical Forum. 1974; 25.

10. Chaput J. Science décalée: lee cannabis ferait grosser les seins des hommes, Futura Santé; 2017.

11. Meyer P, Evaluation et prise en charge d'une gynécomastie, Revue Médicale Suisse. 2009; 5.

12. Lucas LM, Kumar LK, Smith DL, and Gynecomastia: A worrisome problem for the patient, Pos graduates Medicine. 1987: 82.

13. Walls CA, Smith WJ, Draus JM. Gynecomastia in 15-year-old boy, Pediatrics in Review; 2020 